\title{
BMJ Open From menu to mouth: the decay pathway of nutrient intake from planned menu to consumed and characteristics of residents in an aged care facility with greater nutrient decay rates: a cross-sectional study
}

Wathsala Sripali Nanayakkara, ${ }^{1}$ Paula Skidmore, ${ }^{1}$ Leigh O'Brien, ${ }^{1}$ Tim Wilkinson, ${ }^{2}$ Chris Frampton, ${ }^{2}$ Richard Gearry ${ }^{2}$

To cite: Nanayakkara WS, Skidmore P, O'Brien L, et al. From menu to mouth: the decay pathway of nutrient intake from planned menu to consumed and characteristics of residents in an aged care facility with greater nutrient decay rates: a crosssectional study. BMJ Open 2019;9:e024044. doi:10.1136/ bmjopen-2018-024044

- Prepublication history and additional material for this paper are available online. To view these files, please visit the journal online (http://dx.doi. org/10.1136/bmjopen-2018024044).

Received 10 May 2018 Revised 24 September 2019 Accepted 24 September 2019

\section{Check for updates}

(C) Author(s) (or their employer(s)) 2019. Re-use permitted under CC BY-NC. No commercial re-use. See rights and permissions. Published by BMJ.

${ }^{1}$ Department of Human Nutrition, University of Otago, Dunedin, New Zealand

${ }^{2}$ Department of Medicine, University of Otago, Christchurch School of Medicine, Christchurch, New Zealand

Correspondence to Ms Wathsala Sripali Nanayakkara; wathsala.k11@gmail.com

\section{ABSTRACT}

Objectives To observe the cascade of nutrient loss from meals planned to those provided and subsequently consumed by older people in residential care. A secondary aim was to determine the characteristics of residents with higher nutrient loss resulting in lower intake of key nutrients. Design A single-centre cross-sectional study.

Setting An aged residential care facility in Christchurch, New Zealand.

Participants All low and high level of care residents except those who are end of life, enterally fed or on shortterm stay were invited to participate in the study. 54 of 60 selected residents who consumed all three main meals (breakfast, lunch and dinner) for three non-consecutive days were included in the analyses.

Main outcome measures Nutrient contents of planned menu; nutrient contents of meals served and consumed using modified 3-day diet records; and percentage of planned nutrients served and consumed.

Results Vitamins C, B12 and folate had the greatest total decay rates of $50 \%$ or more from that planned to be consumed to what was actually consumed, while unsaturated fats, beta carotene, iodine and zinc had the lowest decay rates of $25 \%$ or less. Male participants and lower care level residents consumed significantly more nutrients, compared with female participants and those receiving higher level care. Increased age, female gender, higher level of care, smaller meal size, pureed diet and lower body mass index were associated with larger decay rates and lower nutrient intakes.

Conclusions Not all planned and served food and beverages are consumed, contributing to potential multiple nutrient deficiencies including energy and protein in the majority of aged-care residents. As a consequence, some nutrients may need to be oversupplied if consumption is to match planned intakes.

\section{INTRODUCTION}

A worldwide high prevalence of malnutrition, specifically protein-calorie undernutrition in older people living in aged-care or
Strengths and limitations of this study

- One researcher had gathered, entered and analysed all data, removing interobserver variability.

- All dietary data were collected using a 3-day diet records (162 food records) where all foods served and consumed were observed and recorded by one researcher, increasing the accuracy of data being collected.

- Included as many participants as possible to provide a true picture of the data being collected.

- Only one aged residential care facility was included in the study, and the results cannot be representative of all residential care facilities in New Zealand.

nursing homes, has been well described. ${ }^{1-5}$ As the population aged over 65 years increases, prevention and early treatment of undernutrition could potentially avoid serious impacts on morbidity and mortality. A recent systematic review ${ }^{6}$ on malnutrition in nursing homes found that approximately half the residents $(47 \%-62 \%)$ were at risk of malnutrition and 20\%-39\% were malnourished. In New Zealand, it is reported that $47 \%$ of older adults recently admitted to age-related residential care are malnourished and a further $43 \%$ are at risk of malnutrition. ${ }^{7}$

Malnutrition or poor nutritional status is associated with multiple adverse outcomes including risk of infections, ${ }^{89}$ pressure sores, ${ }^{10}$ falls, ${ }^{11}$ increased length of hospital stay ${ }^{12}$ and mortality $^{12}$ in older people. Hence, malnutrition affects quality of life and increases healthcare costs. Causes of malnutrition in older people are multifactorial. Some nutritional factors associated with undernutrition include poor appetite, low protein intake, 
slow eating and dysphagia ${ }^{4}$ as well as other known 'geriatric syndromes' such as depression, dementia, functional dependency and multiple comorbidities. ${ }^{13}$ These studies have all looked at the end result of malnutrition. The common response is to ensure that meals in residential care are planned to obviate this problem. However, what is planned is not necessarily what is eaten.

To our knowledge, there are no studies that describe the decay rates of nutrients from the menu to food consumed by residents living in aged-care facilities. Therefore, the purpose of this paper is to assess the 'total decay rate' of selected nutrients between planned meals for an agedcare facility and those actually consumed by the resident. We also aimed to determine the characteristics of residents with higher decay rates and lower intake of key nutrients. In our study, we considered a nutrient to have the greatest decay rate if less than $50 \%$ of the planned nutrient was consumed by the residents. Alternatively, we defined nutrient with the lowest decay rate if more than $75 \%$ of the planned nutrient was consumed.

\section{METHODS}

The protocol for this single-centre cross-sectional study is described elsewhere. ${ }^{14}$ Briefly, residents receiving lower levels of care (rest home) and higher level of nursing and clinical care (hospital level) at a single aged-care facility in Christchurch, New Zealand, were invited to participate in the study. Exclusion criteria were short-term stay, end-of-life, and enterally fed residents. Informed consents were obtained from the participants, next of kin or their legal representative for the study and their clinical records were accessed to obtain weight, height, body mass index (BMI), functional levels, medical diagnoses and medications.

The 4-week cycle menus including recipes were obtained from the facility, and by analysing these menus, the average daily nutrients content was determined for 'meals planned' for the standard serving size used at the facility. The daily menu includes three main meals (breakfast, lunch and dinner), three snacks (morning tea, afternoon tea and supper) and beverages and is designed to meet the recommended daily intakes (RDIs) of most residents. Residents can choose between a 'standard serving' size, and a 'smaller serving' size, which is approximately $50 \%$ the size of the standard serving for lunch and dinner meals. The desserts were served only in standard serving size. Pureed meals (standard size only) were also provided to selected residents who required these. Information on 'meals served' and 'meals consumed' for individual participants were obtained using a combination of weighed/ estimated 3-day diet records to minimise work load and interruptions during meal services. To do this, food items for small and standard serving sizes were weighed using a Salter Model 1010 electronic kitchen scale with accuracy to within $\pm 1 \mathrm{~g}$ (Salter Housewares Ltd, Kent, UK, range 1-2000 g), then each participant's meal was photographed before and after consumption to estimate weights of food or beverage provided and consumed. The weight of the food and beverages consumed was calculated by subtracting the estimated wastage (eg, $0 \%, 25 \%$ and $50 \%$ ) from each served item. A research dietitian collected the diet records for three non-consecutive days (twoweekdays and oneweekend day) for three main meals and three snacks as well as beverages provided (including oral nutritional supplements) and consumed by the participants. 'Meals consumed' also included additional food consumed by participants such as food or beverages brought in by their friends and family or consumed outside the facility as reported by the participant or the family. Where possible, packaging was checked to determine the ingredients and the weight of these extra food or beverages consumed. Similarly, any extra food or beverages consumed overnight (between supper and breakfast) were recorded the next morning from participants who could recall. All nutritional analyses were conducted using FoodWorks 8 Professional Edition (version 8.0.3553, 2015, Xyris Software, Highgate Hill, Australia). Only those participants who consumed all three main meals at the facility (rather than eating outside of the facility) were included for analyses.

Estimated energy requirement was calculated using the Schofield Equation ${ }^{15}$ of $((0.049 \times \mathrm{W})+2.459) \times \mathrm{AF}$ for men and $((0.038 \times \mathrm{W})+2.755) \times \mathrm{AF}$ for women aged $>60$ where $\mathrm{W}$ is for weight and AF is activity factor of 1.2 for bed or chair bound and 1.4 for sedentary but mobile residents. The individual estimated protein requirement was calculated using the recommended $1.07 \mathrm{~g} / \mathrm{kg}$ for males and $0.94 \mathrm{~g} / \mathrm{kg}$ for females. ${ }^{16}$ Average nutrients served and consumed were determined by calculating the average from all individual diet records analysed. These were then compared with either estimated average requirement or adequate intake (AI) for Australia and New Zealand $^{16}$ as applicable for mean nutrient intake by the participants. The percentage of participants meeting the RDI was calculated using the average of 3-day diet records per participant. The average percentage of each nutrient served and consumed was obtained by averaging the individual nutrient results of food records compared with those planned on the menu on the day.

Non-parametric Mann-Whitney $\mathrm{U}$ tests were conducted to compare the percentage of planned nutrients consumed between two groups (ie, gender, level of care and cognitive function). Linear regression models were used to describe the relationships between the decay rates of macronutrients from planned to consumed with age and BMI. A p value of $<0.05$ was considered statistically significant.

\section{Patient and public involvement}

Patients/participants were not involved in the development of the research question and design and outcome measures.

\section{RESULTS}

Data from a total of 54 residents were included in the analyses. Participant characteristics are shown in table 1. The 
Table 1 Baseline demographic and features of 54 participants

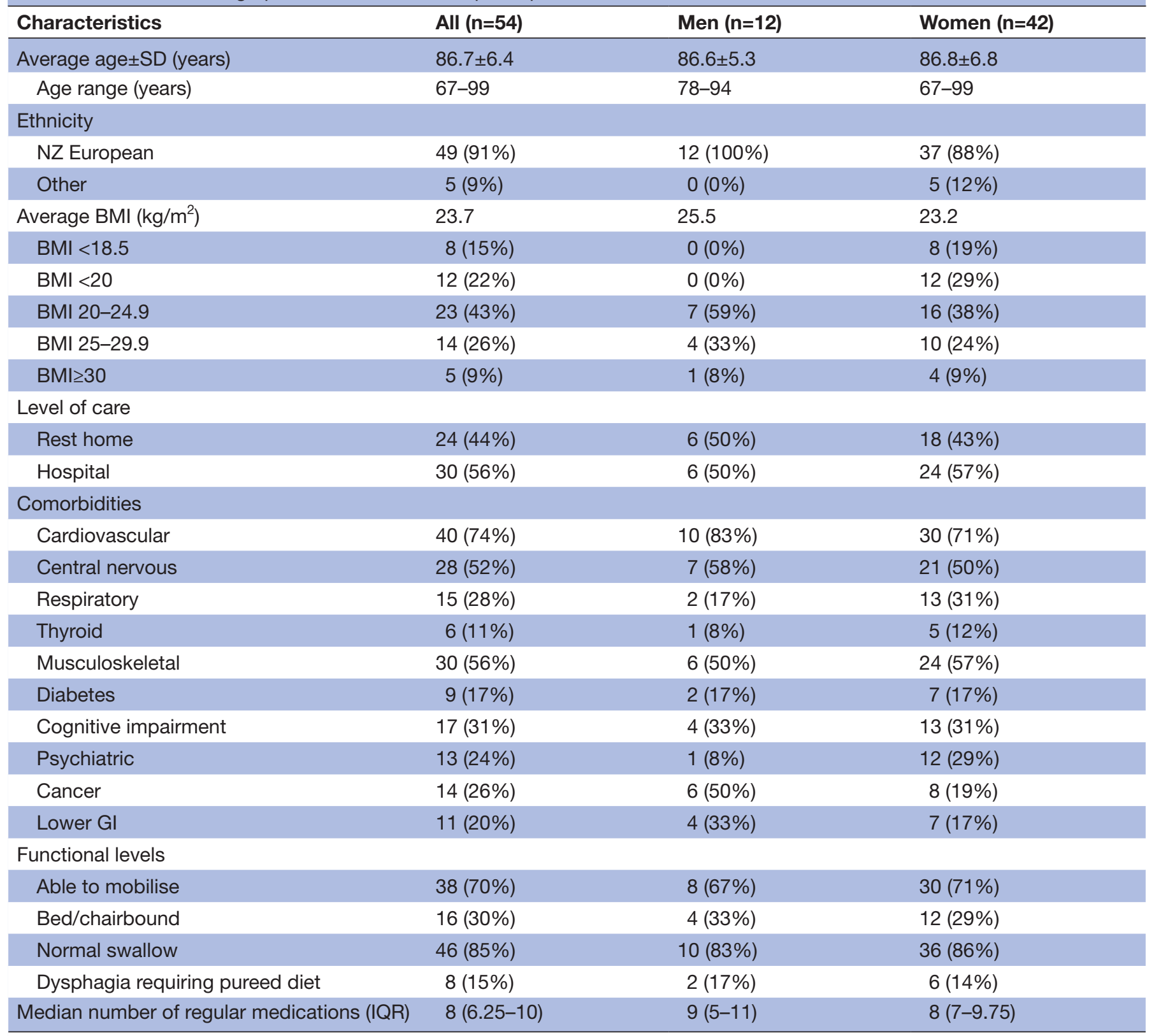

BMI, body mass index; GI, gastrointestinal; NZ, New Zealand.

mean age was $86.7 \pm 6.4$ years, and all except one participant were aged over 70 years. Forty-two participants $(78 \%)$ were women and $56 \%$ of the participants were receiving hospital (high) level of care with $30 \%$ bed or chair bound.

Half of the 54 participants received standard size meals, and the other half received smaller meals for lunch. All male participants received standard meals, while 15 $(36 \%)$ female participants received standard meals, and the remaining were on smaller meals. For macronutrients, a large discrepancy in served protein was seen (residents on smaller meals received $20 \%$ less protein on average compared with those on standard size meals, online supplementary file 1), while least difference was seen in total fats served $(2 \%)$. Both participants on standard and small meals did not consume all nutrients served.
Participants on smaller meals were served and consumed a significantly lower percentage of nutrients from the planned menu compared with standard meals for most nutrients except for total fat, saturated, monounsaturated and polyunsaturated fats and cholesterol, niacin, vitamins $\mathrm{C}$ and E, folic acid, folate, retinol, sodium and iron.

The average nutrients (of 162 diet records) served and consumed by the 54 participants as well as number (\%) of participants meeting the RDIs are summarised in table 2. The menu did not fulfil RDIs or AIs for retinol, water, fibre, magnesium, calcium, phosphorous and iodine. Additionally, the menu exceeded the recommended $\%$ fat contribution to total energy, while \%protein was suboptimal. The majority of participants did not consume enough to meet the RDIs for vitamins E, B6, B12, folate, potassium, iron, 
Table 2 Recommended intakes compared with nutrients planned on the menu, meals served and consumed and number of participants (\%) meeting the recommendation

Average nutrients (\% of planned nutrients) and overall number of participants (\%) who would meet the recommendations according to

\begin{tabular}{|c|c|c|c|c|c|c|c|}
\hline & \multirow{2}{*}{$\begin{array}{l}\text { RDI/AI } \\
\text { Men } \\
>70 \text { years }\end{array}$} & \multirow{2}{*}{$\begin{array}{l}\text { RDI/AI } \\
\text { Women } \\
>70 \text { years }\end{array}$} & \multirow[b]{2}{*}{ Meals planned } & \multicolumn{2}{|c|}{ Served menu } & \multicolumn{2}{|c|}{ Food consumed } \\
\hline & & & & $\begin{array}{l}\text { Average, } n \\
(\%)\end{array}$ & $\begin{array}{l}\text { Overall, n } \\
(\%)\end{array}$ & $\begin{array}{l}\text { Average, } \mathrm{n} \\
(\%)\end{array}$ & $\begin{array}{l}\text { Overall, } \mathrm{n} \\
(\%)\end{array}$ \\
\hline Total protein (g) & $81^{*}$ & $57^{*}$ & 72.1 & $64.1(89)$ & $29(54)$ & $49.8(69)$ & $12(22)$ \\
\hline$\%$ protein & $15-25$ & & 13.8 & 13.4 & $13(24)$ & 13.0 & $8(15)$ \\
\hline Total fat (g) & NA & & 88.5 & $80.8(92)$ & & $65.5(74)$ & \\
\hline Saturated fat (g) & NA & & 40.6 & $35.9(88)$ & & $29.6(72)$ & \\
\hline Polyunsaturated fat (g) & NA & & 10.3 & $10.5(111)$ & & $8.29(88)$ & \\
\hline Monounsaturated fat (g) & NA & & 29.0 & $26.6(94)$ & & $21.3(75)$ & \\
\hline Cholesterol (mg) & NA & & 290 & $26.6(94)$ & & $21.3(75)$ & \\
\hline Water‡ (g) & $3400 \dagger$ & $2800 \dagger$ & 2570 & $2230(86)$ & $0(0)$ & $1550(60)$ & $0(0)$ \\
\hline Fibre (g) & $30 \dagger$ & $25 \dagger$ & 23.1 & $20.3(86)$ & $4(7)$ & $15.8(67)$ & $3(6)$ \\
\hline Total vitamin A equivalent $(\mu \mathrm{g})$ & NA & & 1260 & $1220(96)$ & & $920(73)$ & \\
\hline Retinol $(\mu \mathrm{g})$ & $900^{*}$ & $700^{*}$ & 566 & $496(86)$ & $3(6)$ & $404(69)$ & $0(0)$ \\
\hline Beta carotene equivalents $(\mu \mathrm{g})$ & NA & & 4200 & $4350(121)$ & & $3080(88)$ & \\
\hline Thiamin (mg) & $1.20^{\star}$ & $1.10^{\star}$ & 2.42 & $1.80(74)$ & $37(69)$ & $1.43(60)$ & $29(54)$ \\
\hline Riboflavin (mg) & $1.60^{\star}$ & $1.30^{*}$ & 2.69 & $2.39(87)$ & $49(91)$ & $1.94(71)$ & $48(89)$ \\
\hline Niacin (mg) & NA & & 19.8 & $15.8(79)$ & & $12.4(62)$ & \\
\hline Niacin equivalents (mg) & $16^{*}$ & $14^{*}$ & 34.0 & $28.5(83)$ & $54(100)$ & $22.2(65)$ & $44(81)$ \\
\hline $\begin{array}{l}\text { Total dietary folate equivalent } \\
(\mu \mathrm{g})\end{array}$ & $400^{*}$ & & 841 & $566(66)$ & $35(65)$ & $440(52)$ & $26(48)$ \\
\hline Sodium§ (mg) & 460-920† & & 2400 & $1970(82)$ & $54(100)$ & $1550(64)$ & $53(98)$ \\
\hline Potassium (mg) & $3800 \dagger$ & $2800 \dagger$ & 3320 & $2590(76)$ & $10(19)$ & $2050(61)$ & $3(7)$ \\
\hline Magnesium (mg) & $420^{*}$ & $320^{*}$ & 268 & 257 (94) & $7(13)$ & $201(74)$ & $1(2)$ \\
\hline Calcium (mg) & $1300^{\star}$ & & 871 & 775 (89) & $0(0)$ & $629(72)$ & $0(0)$ \\
\hline Phosphorus (mg) & $1000^{*}$ & & 1320 & $1140(87)$ & $39(72)$ & $917(70)$ & $22(41)$ \\
\hline Iron (mg) & $8^{*}$ & & 14.4 & $9.57(66)$ & $36(67)$ & $7.76(54)$ & $25(46)$ \\
\hline Zinc (mg) & $14^{*}$ & $8^{*}$ & 8.63 & $8.32(97)$ & $21(39)$ & $6.43(75)$ & $8(15)$ \\
\hline Selenium $(\mu \mathrm{g})$ & $70^{*}$ & $60^{*}$ & 60.0 & $52.8(91)$ & $9(17)$ & $40.5(70)$ & $2(4)$ \\
\hline lodine $(\mu \mathrm{g})$ & $150^{*}$ & & 122 & $135(108)$ & $17(31)$ & $103(82)$ & $8(15)$ \\
\hline
\end{tabular}

${ }^{*}$ Recommended dietary requirement.

†Al.

$\ddagger$ Total water includes water from food and fluids.

$\S$ Discretionary salt added during cooking or at the table not included.

$\mathrm{Al}$, adequate intake; IR, individual requirement; NA, not available; RDI, recommended daily intake. 
Table 3 Comparison of average nutrients served and consumed among men and women

\begin{tabular}{|c|c|c|c|c|c|c|}
\hline & \multirow[b]{2}{*}{ Meals planned } & \multicolumn{2}{|c|}{ Meals served ( $\%$ of planned) } & \multicolumn{2}{|c|}{ Meals consumed ( $\%$ of planned) } & \multirow[b]{2}{*}{ P value* } \\
\hline & & Male $(n=12)$ & Female $(n=42)$ & Male $(n=12)$ & Female $(n=42)$ & \\
\hline Energy (kJ) & 8790 & $9010(103)$ & $7780(88)$ & $8000(89)$ & $6000(68)$ & $<0.001$ \\
\hline Total protein (g) & 72.1 & $71.3(96)$ & $62.0(86)$ & $63.3(86)$ & $45.9(65)$ & $<0.001$ \\
\hline$\%$ protein & 13.8 & 13.5 & 13.4 & 13.5 & 12.8 & 0.06 \\
\hline$\%$ fat & 37.8 & 37.5 & 37.5 & 37.6 & 37.9 & 0.74 \\
\hline Total carbohydrates (g) & 244 & $245(99)$ & $216(88)$ & $216(87)$ & $166(68)$ & $<0.001$ \\
\hline$\%$ carbohydrates & 46.4 & 44.6 & 46.3 & 44.2 & 46.4 & 0.29 \\
\hline Water (g) & 2570 & $2590(100)$ & $2120(82)$ & $1990(77)$ & $1430(55)$ & $<0.001$ \\
\hline Fibre (g) & 23.1 & 22.2 (93) & $19.8(85)$ & 19.4 (81) & 14.7 (65) & $<0.001$ \\
\hline
\end{tabular}

*Mann-Whitney $U$ test for \% nutrients consumed between male and female participants.

zinc and selenium in addition to those nutrients noted above.

An average of $8790 \mathrm{~kJ}$ and $72.1 \mathrm{~g}$ of protein per day were planned on the menu; however, on average $91 \%$ of energy and $89 \%$ of protein were served and just $73 \%$ and $69 \%$ of planned energy and protein, respectively, were consumed. The proportions of total fat (74\%) and carbohydrate $(72 \%)$ intake were similar to total energy consumed at $73 \%$. More than half $(61 \%)$ of the participants did not meet their estimated energy requirement, and 39 participants (72\%) did not meet their estimated protein needs.

Nutrients with the greatest decay rates $(<50 \%$ planned nutrients consumed) were: vitamin C (28\%), followed by vitamin B12 (49\%) and folate (49\%). The greatest decay occurred between the amount of nutrients planned and served. The nutrients that were consumed the most with lowest decay rates $(>75 \%$ planned nutrients consumed) were: polyunsaturated fats $(88 \%)$, beta carotenes $(88 \%)$ and iodine $(82 \%)$.
Sixteen $(30 \%)$ of the participants were receiving oral nutritional supplements that provided on average $1330 \mathrm{~kJ}$ (16\% towards total intake per day) and $12.3 \mathrm{~g}$ protein (17\%) served and $1140 \mathrm{~kJ}(21 \%)$ and $9.77 \mathrm{~g}$ protein $(21 \%)$ consumed among these participants on supplements.

Table 3 summarises the differences between men and women for nutrients served and consumed. As mentioned previously, all male participants were served the standard meal serving size, and therefore, the served macronutrients were close to $100 \%$ of that planned, and these participants consumed approximately $90 \%$ of the planned macronutrients. Women where the majority $(64 \%)$ had selected smaller meals at mid-day were served just below $90 \%$ of planned macronutrients on average and consumed approximately $70 \%$ of planned. Hence, there were significant differences $(\mathrm{p}<0.001)$ between men and women for the decay rates for consumed macronutrients except for $\%$ protein, \%fat and \%carbohydrates contribution to total energy.

Table 4 Comparison of average nutrients served and consumed among rest home and hospital level of care participants

\begin{tabular}{|c|c|c|c|c|c|c|}
\hline & \multirow[b]{2}{*}{ Meals planned } & \multicolumn{2}{|c|}{ Meals served ( $\%$ of planned) } & \multicolumn{2}{|c|}{ Meals consumed ( $\%$ of planned) } & \multirow[b]{2}{*}{ P value } \\
\hline & & Rest home ( $n=24)$ & Hospital $(n=30)$ & Rest home ( $n=24)$ & Hospital $(n=30)$ & \\
\hline Energy (kJ) & 8790 & $8300(94)$ & $\begin{array}{l}7860 \\
(88)\end{array}$ & $6950(78)$ & $6040(68)$ & $<0.001$ \\
\hline Energy (kcal) & 2100 & $1980(94)$ & $1880(88)$ & $1660(78)$ & $1440(68)$ & $<0.001$ \\
\hline Total protein (g) & 72.1 & $61.6(85)$ & $66.0(91)$ & $51.1(72)$ & $48.7(68)$ & 0.170 \\
\hline$\%$ fat & 37.8 & 39.5 & 36.2 & 39.8 & 36.5 & 0.003 \\
\hline Total carbohydrates (g) & 244 & $225(91)$ & $220(90)$ & $189(76)$ & $167(68)$ & 0.006 \\
\hline$\%$ carbohydrates & 46.4 & 45.2 & 46.9 & 45.0 & 47.1 & 0.06 \\
\hline Water (g) & 2570 & $2260(87)$ & $2200(85)$ & $1680(65)$ & $1450(57)$ & 0.007 \\
\hline
\end{tabular}

*Mann-Whitney $\mathrm{U}$ test for \% nutrients consumed between rest home and hospital level of care participants. 

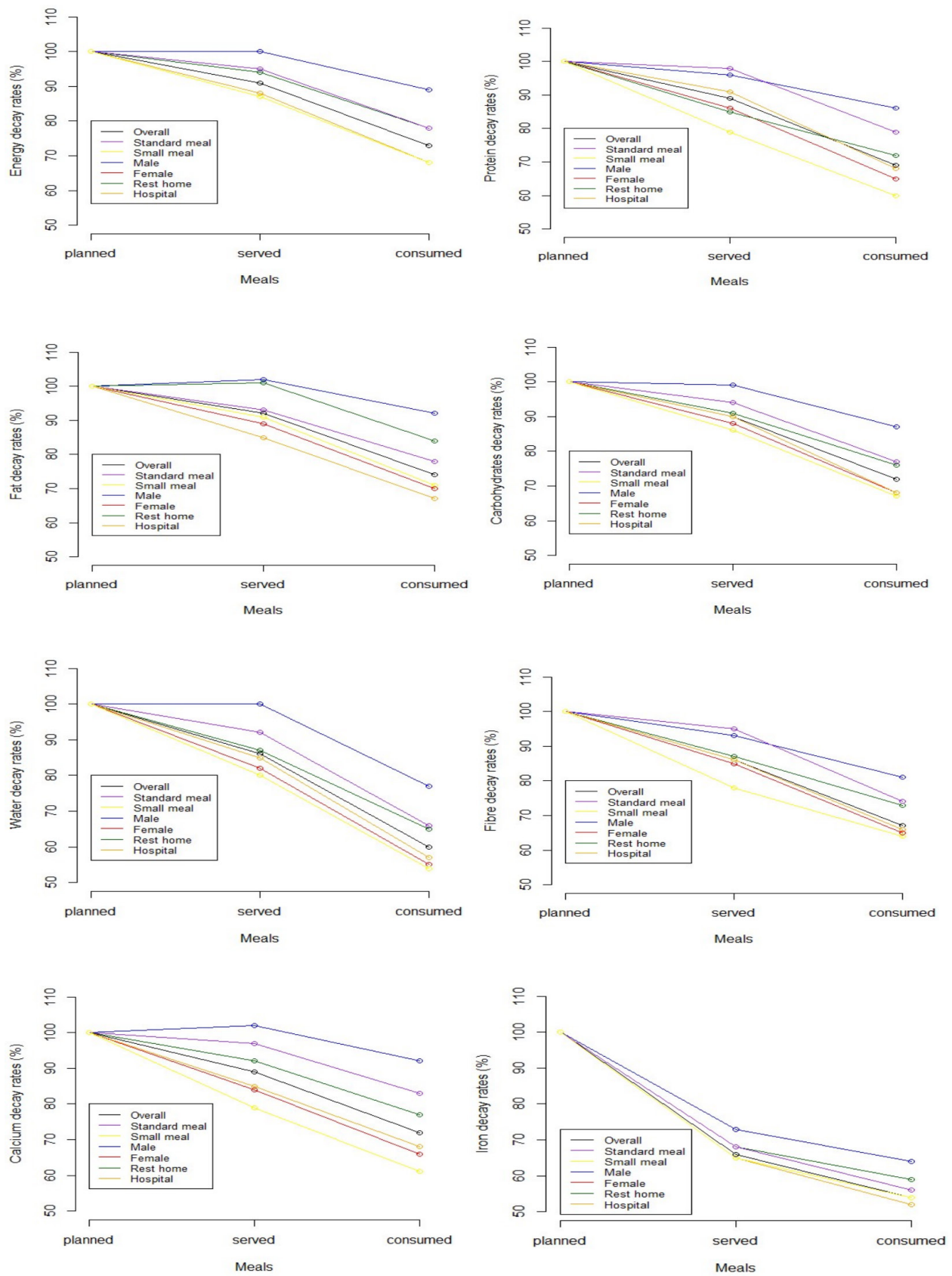

Figure 1 Decay rates of average energy, macronutrients, calcium and iron from planned menu by meal sizes, gender and levels of care.

Table 4 summarises the nutrients served and consumed by rest home and hospital level participants. Hospital level participants had significantly greater decay rates for all nutrients listed $(\mathrm{p}<0.05)$ except for protein and sugar compared with rest home participants. However, hospital participants were served more protein and sugar compared with rest home participants.

Figure 1 depicts the decay rates of average energy, macronutrients, calcium and iron planned, served and consumed by meal size, gender and levels of care. In general, male participants had the smallest decay rates, while small meal size, female and hospital-level participants had the greatest decay rates resulting in lower intakes of energy and nutrients. Female and hospital participants had the same decay patterns for energy and iron.

Seven $(41 \%)$ of the participants with cognitive impairment were either assisted or fully fed by the staff. The decay rates were similar, and there were no statistically significant differences between those with or without cognitive impairment (online supplementary file 2). Similarly, there were no significant differences between the decay rates of macronutrients between mobile and bed or chair-bound participants (online supplementary file 3). In contrast, six participants who received pureed meals consumed significantly lower total energy, fat, carbohydrates and water with 
greater decay rates compared with participants on regular textured diet (online supplementary file 4).

Linear regression models showed significant negative associations between decay rates (from planned to consumed nutrients) and age for macronutrients. Specifically, the reductions were $11.5 \%(\mathrm{p}=0.004)$ for energy, $12.5 \%(\mathrm{p}=0.005)$ for protein, 9.7\% $(\mathrm{p}=0.055)$ for fat and $11.7 \%(\mathrm{p}=0.003)$ for carbohydrates for every 10-year increase in age. Similarly, there were significant negative associations between decay rates and BMI. These reductions were $16.5 \%(\mathrm{p}=0.002)$ for energy, $14.3 \%(\mathrm{p}=0.020)$ for protein, $17.5 \%(\mathrm{p}=0.010)$ for fat and $14.7 \%(\mathrm{p}=0.007)$ for carbohydrates for every $10 \mathrm{~kg} / \mathrm{m}^{2}$ decline in BMI.

\section{DISCUSSION}

To our knowledge, this is the first study to investigate the cascade effect of nutrient intake decay from a planned menu to what is actually consumed by residents living in an aged-care facility. Our primary aim was to observe the total decay rate (percentage of planned nutrients consumed by the residents) to help identify those who are most at risk of inadequate nutrient intake. The results showed that not all food and beverages served were consumed by the residents. Those consuming smaller size meals, female and hospital (high) level of care participants had the greatest decay rates for total energy, macronutrients, iron and calcium. We acknowledge that in our study, only female residents $(64 \%$ of female residents) had selected small meal size, and the decay rates for meals served and consumed are affected for women for this reason. Among macronutrients, least decay rates were seen in fats followed by carbohydrates and protein had the greatest decay rates. While protein intake is known to be important in older adults, particularly to prevent or reduce the effects of sarcopenia, our study indicated that the majority $(72 \%)$ of aged-care residents did not consume adequate protein. Similarly $61 \%$ of these residents did not meet their estimated energy requirements. Furthermore, increasing age and reduction in BMI were also associated with significantly lower energy and macronutrient intake.

We found that vitamin $\mathrm{C}$ had the greatest decay rates; however, $91 \%$ of the participants were served and $63 \%$ consumed the recommended $45 \mathrm{mg} /$ day on average. The discrepancy was due to the fact that vitamin C-rich items such as orange juice, cranberry juice and kiwifruit on the menu were not necessarily selected by the participants. Additionally, not all participants consumed all of the canned or fresh fruit being served, hence the drop in percentage of residents meeting the recommended intake. Other common food wastes that contributed to decay rates of macronutrients included bread or toast, particularly the crusts, preordered sandwiches at the evening meal, coleslaw, green salads, milk served with breakfast cereals, porridge and in tea, meats, pasta dishes, instant puddings offered as pureed desserts, some vegetables such as courgettes, leeks and cabbage. The greater decay rates of protein may be due to items such as meats and milk-containing food and beverages being left unconsumed. However, it was evident that the $\%$ protein contribution to total energy was below recommendation and \% fat exceeded the recommended level on the menu, and those participants on smaller meals were served significantly less protein (meats) but similar amounts of fats to those on standard serving size.

We did not observe any significant differences in nutritional intake or decay rates between those with cognitive impairment and those without. All food intakes from breakfast to supper were observed; however, the details of food consumed overnight were collected from those who could recall. We believe that this would not have made a significant impact on the results as the menu (which covers all food offered from breakfast to supper) is intended to meet most residents' nutritional requirements. The reason for not observing significant differences may be due to feeding assistance provided by staff to $41 \%$ of the participants with cognitive impairment. Indeed, the provision of regular feeding or eating assistance has been shown to improve food intake in agedcare residents. ${ }^{17}$ However, feeding assistance is often not provided in care facilities due to staff and time constraints. Provision of such assistance is also important since malnourished patients are more likely to consume $\leq 50 \%$ meals compared with well-nourished patients. ${ }^{18}$

Our study found that, on average, residents consumed $6440 \mathrm{~kJ}$ ( $1540 \mathrm{kcal} /$ day), which is similar to that described in previously published studies ${ }^{17-22}$ (average 1507-1522 $\mathrm{kcal} /$ day). However, the average protein intake of $49.8 \mathrm{~g} /$ day was much lower than that described previously ${ }^{1720-22}$ (54.8-58g/day). Similar to our study, Buckinx $e t a l^{21}$ also found that not all meals served in nursing homes were consumed by the residents and that there were significant differences between energy and macronutrient contents of foods served and consumed. Equally, a Canadian study ${ }^{19}$ found that despite an average normal BMI, these elderly residents did not meet the requirements for macronutrient and micronutrient intake. These studies support our findings that the majority of aged-care residents are at risk of nutritional inadequacy.

It is important to note that although we found that male participants had the lowest decay rates for nutrients, the majority of study participants including men were found to have inadequate consumption of multiple nutrients namely protein, water, fibre, vitamins A, E, B6, B12, folate, potassium, magnesium, calcium, phosphorus, iron, zinc, selenium and iodine. Unfortunately, the RDI of 11 (69\%) of these 16 nutrients was not met by the planned menu, particularly for men who have higher RDIs.

We should emphasise that a residential care institution should deliberately plan to oversupply meals to its residents, rather than not serving enough. This means that what is served should, on average, always be greater than what is consumed. However, this is the first study to quantify these gaps and to show which nutrients may be at greater risk of being underconsumed. However, serving meals that are too large can discourage people from eating. A solution may be to offer second servings at meal 
times and to offer snacks between meals. In both cases, ideally, these would be oversupplied with nutrients known to be at risk, such as protein, fibre, vitamins A, B6, magnesium, calcium and zinc. Furthermore, given protein had one of the greater decay rates, the menu should focus on offering more protein at each meal rather than fats as fats are generally well consumed by the residents.

As with any study, there are potential limitations to this research. As all recruitment occurred at one facility, and all participants were Caucasian, the study participants may not be representative of all New Zealand aged-care facilities. One research dietitian collected all dietary data eliminating interobserver error and used weighed food record in combination with a validated visual assessment method of plate waste. ${ }^{23}$ Our study did not screen for malnutrition; however, $22 \%$ of the participants were found to have low BMI $\left(<20 \mathrm{~kg} / \mathrm{m}^{2}\right.$ including $15 \%$ with BMI $\left.<18.5\right)$. We suggest future studies compare differences in nutrient intake between well-nourished and malnourished residents identified using a nutritional screening tool such as Mini Nutritional Assessment. ${ }^{24}$ Some important nutrients such as vitamin D were not analysed in this study; however, they could be assessed in future studies.

\section{CONCLUSION}

Despite menu planning, approximately $90 \%$ of nutrients planned on the menu are served to the residents and about $70 \%$ are consumed. Subsequently, multiple nutrient deficiencies exist including suboptimal energy and protein intake in aged-care residents in New Zealand. Female sex, increasing age, smaller meal size, hospital level of care, lower BMI and consuming a pureed diet were associated with lower nutrient intake with greater nutrient decay rates. However, male residents were more likely to consume most of nutrients planned and served at the facility. The study highlighted the need to increase protein and energy content on the menu, and we suggest routinely offering protein-rich snacks as in-between meal snacks and offering larger meals or alternatively second helping to residents.

Contributors WSN, RG, LO, TW and PS were responsible for the planning of this study. WSN was responsible for participant recruitment, data collection and entry and drafting the manuscript under the supervision of RG, LO, TW and PS; CF was responsible for support with statistical analysis and reporting. All authors provided critical review and revision of the manuscript and have read and approved the final version of the manuscript.

Funding The authors have not declared a specific grant for this research from any funding agency in the public, commercial or not-for-profit sectors.

Competing interests None declared.

Patient consent for publication Not required.

Ethics approval The study was approved by The University of Otago Human Ethics (Health) Committee (H15/053).

Provenance and peer review Not commissioned; externally peer reviewed.

Data availability statement № data are available.

Open access This is an open access article distributed in accordance with the Creative Commons Attribution Non Commercial (CC BY-NC 4.0) license, which permits others to distribute, remix, adapt, build upon this work non-commercially, and license their derivative works on different terms, provided the original work is properly cited, appropriate credit is given, any changes made indicated, and the use is non-commercial. See: http://creativecommons.org/licenses/by-nc/4.0/.

\section{REFERENCES}

1 Borgstrom Bolmsjo B, Jakobsson U, Molstad S, et al. The nutritional situation in Swedish nursing homes - a longitudinal study. Archives of gerontology and geriatrics 2015;60:128-33.

2 Gaskill D, Black LJ, Isenring EA, et al. Malnutrition prevalence and nutrition issues in residential aged care facilities. Australas $J$ Ageing 2008;27:189-94.

3 Kaiser MJ, Bauer JM, Rämsch C, et al. Frequency of malnutrition in older adults: a multinational perspective using the mini nutritional assessment. J Am Geriatr Soc 2010;58:1734-8.

4 Keller HH. Malnutrition in institutionalized elderly: how and why? J Am Geriatr Soc 1993;41:1212-8.

5 Saletti A, Lindgren EY, Johansson L, et al. Nutritional status according to mini nutritional assessment in an institutionalized elderly population in Sweden. Gerontology 2000;46:139-45.

6 Bell CL, Tamura BK, Masaki KH, et al. Prevalence and measures of nutritional compromise among nursing home patients: weight loss, low body mass index, malnutrition, and feeding dependency, a systematic review of the literature. J Am Med Dir Assoc 2013;14:94-100.

7 Watkin RS, Gammon CS, Allen J, et al. Screening for nutrition risk and dysphagia among older adults recently admitted to age related residential care within the waitemata dhb region. Nutrients. Conference: Nutrition Society of New Zealand Annual Conference 2016;9.

8 Gavazzi G, Krause K-H. Ageing and infection. Lancet Infect Dis 2002;2:659-66.

9 Schneider SM, Veyres P, Pivot X, et al. Malnutrition is an independent factor associated with nosocomial infections. Br J Nutr 2004;92:105-11.

10 Shahin ESM, Meijers JMM, Schols JMGA, et al. The relationship between malnutrition parameters and pressure ulcers in hospitals and nursing homes. Nutrition 2010;26:886-9.

11 Johnson CS. The association between nutritional risk and falls among frail elderly. J Nutr Health Aging 2003;7:247-50.

12 Stratton RJ, King CL, Stroud MA, et al. 'Malnutrition Universal Screening Tool' predicts mortality and length of hospital stay in acutely ill elderly. British Journal of Nutrition 2006;95:325-30.

13 Saka B, Kaya O, Ozturk GB, et al. Malnutrition in the elderly and its relationship with other geriatric syndromes. Clinical Nutrition 2010;29:745-8

14 Nanayakkara W, Gearry R, Muir J, et al. Gastrointestinal symptoms and FODMAP intake of aged-care residents from Christchurch, New Zealand. Nutrients 2017;9:1083.

15 Schofield WN. Predicting basal metabolic rate, new standards and review of previous work. Human nutrition. Clinical nutrition 1985;39:5-41.

16 National Health and Medical Research Council AGDoHaA, New Zealand Minisry of Health. Nutrient reference values for Australia and New Zealand including recommended dietary intakes. Canberra 2006.

17 Keller HH, Carrier N, Slaughter SE, et al. Prevalence and determinants of poor food intake of residents living in long-term care. J Am Med Dir Assoc 2017;18:941-7.

18 Agarwal E, Ferguson M, Banks M, et al. Nutritional status and dietary intake of acute care patients: results from the nutrition care day survey 2010. Clinical Nutrition 2012;31:41-7.

19 Aghdassi E, McArthur M, Liu B, et al. Dietary intake of elderly living in Toronto long-term care facilities: comparison to the dietary reference intake. Rejuvenation Res 2007;10:301-10.

20 Iuliano S, Poon S, Wang X, et al. Dairy food supplementation may reduce malnutrition risk in institutionalised elderly. British Journal of Nutrition 2017;117:142-7.

21 Buckinx F, Allepaerts S, Paquot N, et al. Energy and nutrient content of food served and consumed by nursing home residents. J Nutr Health Aging 2017;21:727-32.

22 Iuliano S, Olden A, Woods J. Meeting the nutritional needs of elderly residents in aged-care: are we doing enough? J Nutr Health Aging 2013;17:503-8.

23 Sherwin AJ, Nowson CA, McPhee J, et al. Nutrient intake at meals in residential care facilites for the aged: validated visual estimation of plate waste 1998;55:188-93.

24 Guigoz Y, Vellas B, Garry PJ. Assessing the nutritional status of the elderly: the mini nutritional assessment as part of the geriatric evaluation. Nutr Rev 1996;54:S59-65. 